\title{
Outcome of Adults with Leptospirosis and Renal Failure Treated with Pulse Immunosuppression
}

\section{Pasamba EM ${ }^{1 *}$, Arakama $\mathbf{M I}^{1}$, Danguilan $\mathrm{RA}^{1}$ and Mendoza $\mathrm{MT}^{2}$}

${ }^{1}$ Department of Adult Nephrology, National Kidney and Transplant Institute, Philippines

${ }^{2}$ Department of Internal Medicine, National Kidney and Transplant Institute, Philippines

"Corresponding author: Edmundo M Pasamba, Department of Adult Nephrology, National Kidney and Transplant Institute, East Avenue Diliman, Quezon City, Metro Manila, Philippines, Tel: $\quad$ +639063251250; E-mail: mon.pasamba@gmail.com

Received date: Jan 18, 2018; Accepted date: Feb 01, 2018; Published date: Feb 07, 2018

Copyright: (c) 2018 Pasamba EM, et al. This is an open-access article distributed under the terms of the Creative Commons Attribution License, which permits unrestricted use, distribution, and reproduction in any medium, provided the original author and source are credited.

\begin{abstract}
Introduction: Leptospirosis presenting with renal failure is often accompanied by pulmonary hemorrhage and carries a high mortality despite standard therapy. There is increasing evidence for an immunologic mechanism mediating both these complications hence methylprednisolone and cyclophosphamide were adapted in the treatment protocol to improve overall outcome.
\end{abstract}

Methods: This is a retrospective review of adults with leptospirosis and renal failure admitted at National Kidney and Transplant Institute from January 2014 to December 2016 treated with pulse immunosuppression followed up until hospital discharge. Primary outcome is overall survival while secondary outcomes include predictors of mortality, length of hospital stay, number of days on hemodialysis, use of blood products and occurrence of nosocomial infection.

Results: Among 194 patients included in the study, 49 (25\%) patients died; 32 (16\%) due to pulmonary hemorrhage, $13(7 \%)$ due to multiple organ failure and $4(2 \%)$ due to hospital acquired pneumonia. The $13 \%$ who developed pneumonia had a significantly longer hospital stay ( $p$-value 0.0021). Significant predictors of mortality included a low platelet count ( $p$-value $<0.001$ ), prolonged prothrombin time ( $p$-value 0.026 ) and presence of parenchymal infiltrates on chest radiograph ( $p$-value 0.001). Transfusion with platelet concentrate and fresh frozen plasma were significantly higher among patients who died ( $p$-value of $<0.001$ and 0.042 respectively). Most patients were weaned off hemodialysis after an average of 2 days.

Conclusion \& Recommendation: Although majority of patients survived this catastrophic disease, there was $25 \%$ mortality among patients in the study and majority died from pulmonary hemorrhage. Abnormal bleeding parameters and parenchymal infiltrates on chest radiograph significantly predicted death. Renal function recovered within 2 days of treatment regardless of mortality outcome. Pulmonary supportive therapy such as extracorporeal membrane oxygenation should be investigated to improve survival among patients with pulmonary hemorrhage.

Keywords: Acute kidney injury; Cyclophosphamide; Methylprednisolone; Pulmonary haemorrhage; Weil's disease

\section{Introduction}

Leptospirosis is a bacterial disease of humans and animals caused by pathogenic Leptospira species. Human infection is through direct contact with the urine of infected animals or with a urinecontaminated environment (through cuts or abrasions on the skin or via the mucous membranes of the mouth, nose and eyes). Its spectrum of clinical manifestation ranges from a self-limiting mild disease (fever, headache and myalgia) to a fulminant and fatal disease (Weil's disease [jaundice, renal failure and pulmonary hemorrhage] and meningitis). It has a worldwide distribution but is more prevalent in tropical and subtropical regions. Outbreaks can occur following excessive rainfall or flooding [1-3].

In the Philippines, the heavy rainfall of Typhoon Ondoy in 2009 increased the cases of leptospirosis seen at the National Kidney and Transplant Institute (NKTI). Mortality was high at 26\% (16 out of 64 patients) despite standard therapy. Death was primarily from pulmonary hemorrhage hence the treatment protocol was revised to include a 3 day course of hydrocortisone. An unpublished report by Quilala et al. in 2010 investigated the effect of this new protocol on patient survival and found no significant difference in the risk of death among patients given steroids versus supportive therapy alone $(15.7 \%$ vs. $14.1 \%)$. However, the mean time prior to death was longer among patients given steroids and pulmonary hemorrhage was higher among patients on standard therapy alone.

Monsoon rains that led to widespread flooding in Metro Manila in 2012 again resulted in increased cases of leptospirosis at NKTI and mortality remained high at $28 \%$ (14 out of 51 patients) despite 3 day course of hydrocortisone and standard therapy.

There has been increasing evidence for an immunologic mechanism mediating renal failure and pulmonary hemorrhagic complications in leptospirosis via an exaggerated host immune response [4,5], thus the NKTI treatment protocol was revised to add a 3 day course of methylprednisolone and a single dose of intravenous cyclophosphamide to improve the overall outcome of these patients [6,7]. Manipol-Lorano et al. in 2014 compared this amended protocol 
to a historical control given a 3 day course of hydrocortisone. Their study showed a significant survival benefit ( $88 \%$ vs. $74 \%)$ as well as improvement in the levels of partial thromboplastin time [8]. Thus, pulse immunosuppression remains the standard therapy for patients with leptospirosis and renal failure. This review will examine patient outcomes in the last 3 years using this immunosuppressive therapy.

\section{Significance of the Study}

The high mortality associated with leptospirosis with renal and lung failure warrants continuous study. Leptospirosis usually affects the young labor force of the country, who usually comprise the family's principal breadwinners. Efforts should be exerted to analyze the causes of its high mortality in order to effectively improve treatment options. The use of pulse immunosuppression as standard treatment, with its attendant risks, in this already highly morbid disease, should be carefully monitored.

\section{General Objective}

To determine the outcome of adults with leptospirosis and renal failure treated with pulse immunosuppression.

\section{Specific Objectives}

To determine overall survival of adults with leptospirosis and renal failure treated with methylprednisolone and cyclophosphamide until hospital discharge.

To look for predictors of mortality in the demographics and baseline examinations.

To determine the burden of disease in terms of length of hospital stay, number of days on hemodialysis and use of blood products.

To document the occurrence of nosocomial infection with pulse immunosuppression.

\section{Methods}

\section{Study design}

This is a retrospective review of adults with leptospirosis and renal failure admitted at NKTI from January 2014 to December 2016 treated with pulse immunosuppression followed up until hospital discharge.

\section{Study subjects}

Inclusion criteria: Patients with a presumptive diagnosis of leptospirosis aged 18 years old and above with renal failure and fulfilled one or more of the criteria for pulse immunosuppression based on NKTI guidelines [9].

Platelet count $<100,000 \mathrm{~m}^{3}$.

Systolic blood pressure $<90 \mathrm{~mm} \mathrm{H}_{2} \mathrm{O}$ after fluid resuscitation of 2 liters isotonic saline solution and requires inotropic support.

Lung infiltrates on chest radiograph.

Prothrombin time (PT) and partial thromboplastin time (PTT) at 1.5 times more than the control value.

Treatment protocol of NKTI leptospirosis is shown in the Figure 1.

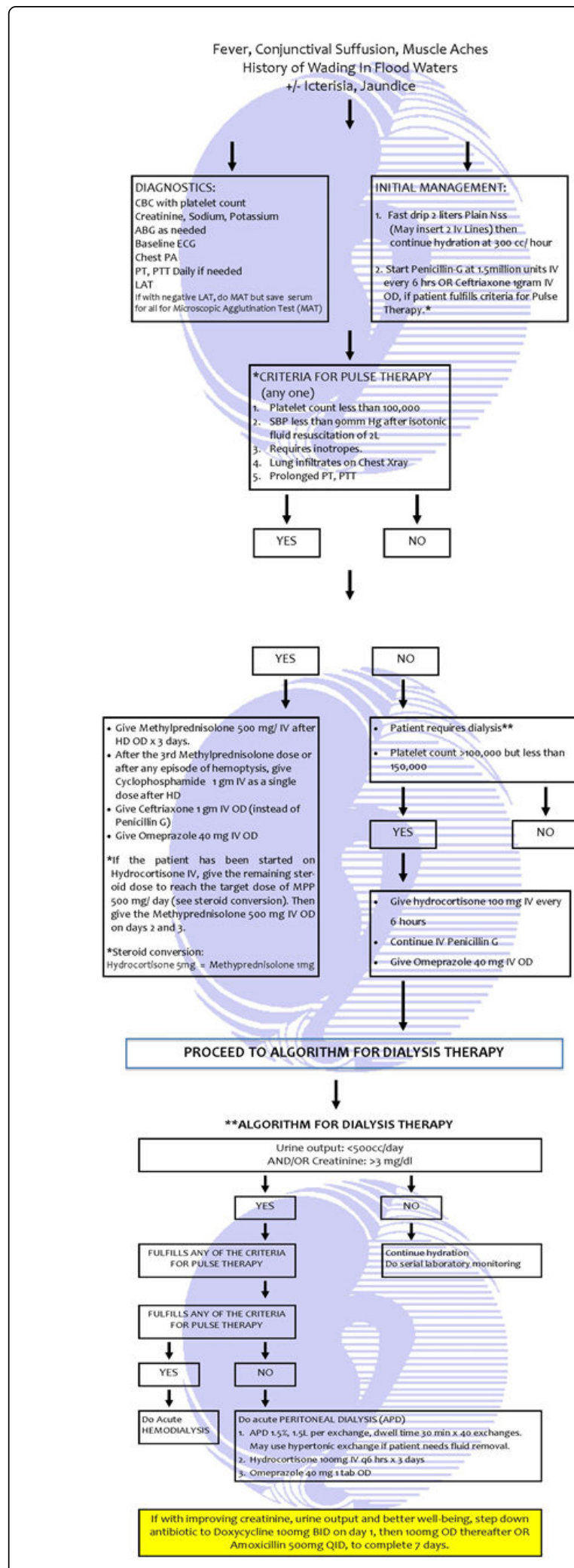

Figure 1: NKTI leptospirosis treatment protocol. 
Citation: Pasamba EM, Arakama MI, Danguilan RA, Mendoza MT (2018) Outcome of Adults with Leptospirosis and Renal Failure Treated with

Page 3 of 6

Exclusion criteria: Patients who died within 24 hours from admission.

Patients with chronic kidney disease.

Patients discharged against medical advice without completing the treatment protocol.

\section{Definition of Terms}

Leptospirosis: Patients diagnosed presumptively as leptospirosis (fever, conjunctival suffusion, muscle aches, history of wading in flood waters, icterisia and jaundice) who develops thrombocytopenia (platelet count $<100,000 \mathrm{~m}^{3}$ ), hypotension requiring inotropic support (systolic blood pressure $<90 \mathrm{mmH}_{2} \mathrm{O}$ despite adequate fluid challenge), lung infiltrates on chest radiograph, deranged bleeding parameters and pulmonary hemorrhage.

Renal failure: Leptospirosis patients with oliguria (urine output $<500 \mathrm{cc} /$ day) and/or serum creatinine $>3 \mathrm{mg} / \mathrm{dL}$.

Standard treatment: Supportive care, IV hydration with normal saline, empiric antibiotic (ceftriaxone $1 \mathrm{gm} \mathrm{IV} \mathrm{q24),} \mathrm{inotropic} \mathrm{support}$ (dopamine or norepinephrine), hemodialysis, ventilator support and/or use of blood products when required [9].

Pulse immunosuppression/Treatment protocol: 3 day course of methylprednisolone $500 \mathrm{mg}$ IV followed by a single dose of cyclophosphamide 1 gm IV (Figure 1) [9].

Hospital acquired pneumonia: Presence of cough with purulent secretion, fever and/or new pneumonic infiltrate on chest radiograph beyond 48 hours of admission.

\section{Data collection}

Charts of patients admitted for leptospirosis from January 2014 to December 2016 were reviewed at NKTI Medical Records Section and those who passed the inclusion and exclusion criteria were included in the study. Demographics, baseline work-ups, length of hospital stay, number of days on hemodialysis, use of blood products (packed red blood cell, platelet concentrate or fresh frozen plasma), occurrence of nosocomial infection and survival were reviewed and encoded in a password protected microsoft excel spreadsheet.

\section{Outcomes}

Primary outcome is overall survival among patients given pulse immunosuppression. Secondary outcomes include predictors of mortality, length of hospital stay, number of days on hemodialysis, use of blood products and occurrence of nosocomial infection.

\section{Data analysis}

Descriptive statistics (mean and standard deviation) for baseline characteristics and outcomes were computed and corresponding statistical analysis ( $\chi^{2}$ and T-test) were done to look for significant difference between patients who lived from those who died.

\section{Ethical considerations}

The study was approved by the institute's research ethics committee. Confidentiality and anonymity was maintained by assigning a specific number to each of the subjects and allowing only the primary investigator and designated research assistant access and view of the data.

\section{Result}

A total of 194 patients were included in the study. Majority (89\%) were male and mean age was 37 years old. Most (84\%) were from NCR due to its proximity with NKTI. Majority $(94 \%)$ of the patients who died came from NCR (p-value 0.029) (Table 1).

\begin{tabular}{|c|c|c|c|c|}
\hline & $\begin{array}{l}\text { Total } \\
n=194\end{array}$ & $\begin{array}{l}\text { Lived } \\
\mathrm{n}=145\end{array}$ & $\begin{array}{l}\text { Died } \\
n=49\end{array}$ & p-value \\
\hline Age (Years) & $37 \pm 13$ & $37 \pm 13$ & $38 \pm 14$ & 0.947 \\
\hline \multicolumn{4}{|l|}{ Sex } & 0.452 \\
\hline Male & $172(89 \%)$ & $130(90 \%)$ & $42(86 \%)$ & \\
\hline Female & $22(11 \%)$ & $15(10 \%)$ & $7(14 \%)$ & \\
\hline \multicolumn{4}{|l|}{ Region } & ${ }^{*} 0.029$ \\
\hline $\mathrm{NCR}^{+}$ & $163(84 \%)$ & $117(81 \%)$ & $46(94 \%)$ & \\
\hline Outside $\mathrm{NCR}^{+}$ & $31(16 \%)$ & $28(19 \%)$ & $3(6 \%)$ & \\
\hline \multicolumn{4}{|l|}{ Occupation } & 0.846 \\
\hline Unemployed & $97(50 \%)$ & $73(50 \%)$ & $24(50 \%)$ & \\
\hline Driver & $17(9 \%)$ & $14(10 \%)$ & $3(6 \%)$ & \\
\hline Vendor & $9(5 \%)$ & $7(5 \%)$ & $2(4 \%)$ & \\
\hline Construction Worker & $24(12 \%)$ & $16(11 \%)$ & $8(16 \%)$ & \\
\hline Garbage Collector & $4(2 \%)$ & $3(2 \%)$ & $1(2 \%)$ & \\
\hline Office Worker & $4(2 \%)$ & $4(3 \%)$ & $0(0 \%)$ & \\
\hline Messenger & $2(1 \%)$ & $2(1 \%)$ & $0(0 \%)$ & \\
\hline Fisherman/Farmer & $5(3 \%)$ & $4(3 \%)$ & $1(2 \%)$ & \\
\hline Others & $32(16 \%)$ & $22(15 \%)$ & $10(20 \%)$ & \\
\hline \multicolumn{4}{|l|}{ Exposure History } & 0.399 \\
\hline Wading in Flood Water & $\begin{array}{l}177 \\
(91 \%)\end{array}$ & $131(90 \%)$ & $46(94 \%)$ & \\
\hline None & $17(9 \%)$ & $14(10 \%)$ & $3(6 \%)$ & \\
\hline \multicolumn{4}{|l|}{ Co-morbid Illness } & 0.238 \\
\hline None & $\begin{array}{l}168 \\
(87 \%)\end{array}$ & $128(88 \%)$ & $40(82 \%)$ & \\
\hline With Co-morbidity & $26(13 \%)$ & $17(12 \%)$ & $9(18 \%)$ & \\
\hline $\begin{array}{l}\text { Lung Disease (Asthma/ } \\
\left.\text { COPD }{ }^{\ddagger}\right)\end{array}$ & $9(4 \%)$ & $5(3 \%)$ & $4(8 \%)$ & \\
\hline Hypertension & $10(5 \%)$ & $7(5 \%)$ & $3(6 \%)$ & \\
\hline Type 2 Diabetes Mellitus & $5(3 \%)$ & $4(3 \%)$ & $1(2 \%)$ & \\
\hline Others & $2(1 \%)$ & $1(1 \%)$ & $1(2 \%)$ & \\
\hline
\end{tabular}

Table 1: Demographics and patient characteristics. 
Citation: Pasamba EM, Arakama MI, Danguilan RA, Mendoza MT (2018) Outcome of Adults with Leptospirosis and Renal Failure Treated with

Page 4 of 6

Half of the patients were unemployed. Among those who worked, majority had blue-collared occupations. Majority (91\%) had history of wading in flood waters. Most (87\%) had no co-morbidities. Other than region, there was no significant difference among patients who survived versus those who died based on patient demographics (Table 1).

Although majority (75\%) of the patients recovered from this severe disease, 49 (25\%) patients who died mainly from pulmonary hemorrhage in $16 \%$, followed by multiple organ failure in $7 \%$ and hospital acquired pneumonia in 2\% (Table 2). Patients who died of multiple organ failure did not have pulmonary hemorrhage.

The following factors were significant predictors of mortality: Mean platelet count less than $64 \times 10^{3} / \mathrm{uL} \pm 56$ (p-value<0.001), PT more than $15 \pm 5$ seconds ( $\mathrm{p}$-value 0.026 ) and presence of parenchymal infiltrates on chest radiograph ( $\mathrm{p}$-value 0.001). There was no significant difference seen with hemoglobin, white blood cell count, creatinine, PTT and LAT (Table 3).

\begin{tabular}{|l|l|l|}
\hline & Number & Percentage \\
\hline Number of Patients & 194 & 100 \\
\hline Lived & 145 & 75 \\
\hline Died & 49 & 25 \\
\hline Pulmonary Hemorrhage & 32 & 16 \\
\hline Multiple Organ Failure & 13 & 7 \\
\hline Hospital Acquired Pneumonia & 4 & 2 \\
\hline
\end{tabular}

Table 2: Primary outcome.

\begin{tabular}{|c|c|c|c|c|}
\hline & $\begin{array}{l}\text { Total } \\
n=194\end{array}$ & $\begin{array}{l}\text { Lived } \\
\mathrm{n}=145\end{array}$ & $\begin{array}{l}\text { Died } \\
n=49\end{array}$ & $p$-value \\
\hline Hemoglobin (g/dL) & $13 \pm 2$ & $13 \pm 2$ & $13 \pm 2$ & 0.895 \\
\hline $\mathrm{WBC}^{+}\left(\times 10^{3} / \mathrm{uL}\right)$ & $15 \pm 6$ & $14 \pm 6$ & $16 \pm 7$ & 0.095 \\
\hline $\begin{array}{l}\text { Platelet Count } \\
\text { (x 103/uL) }\end{array}$ & $101 \pm 76$ & $113 \pm 78$ & $64 \pm 56$ & ${ }^{*}<0.001$ \\
\hline Creatinine & $8 \pm 3$ & $8 \pm 3$ & $8 \pm 3$ & 0.659 \\
\hline $\mathrm{PT}^{\ddagger}(\mathrm{sec})$ & $14 \pm 3$ & $14 \pm 2$ & $15 \pm 5$ & ${ }^{*} 0.026$ \\
\hline $\mathrm{PTT}^{\S}$ (sec) & $44 \pm 12$ & $44 \pm 10$ & $47 \pm 15$ & 0.121 \\
\hline \multicolumn{4}{|l|}{ LAT } & 0.134 \\
\hline Positive & $42(22 \%)$ & $29(20 \%)$ & $14(29 \%)$ & \\
\hline Negative & $151(78 \%)$ & $116(80 \%)$ & $35(71 \%)$ & \\
\hline \multicolumn{4}{|l|}{ Chest Radiograph } & ${ }^{*} 0.001$ \\
\hline Clear lungs & $112(58 \%)$ & $94(65 \%)$ & $18(37 \%)$ & \\
\hline Parenchymal infiltrates & $82(42 \%)$ & $51(35 \%)$ & $31(63 \%)$ & \\
\hline
\end{tabular}

Table 3: Baseline laboratories and radiology.

Extra-pulmonary bleeding and pulmonary hemorrhage were significantly higher among patients who died (p-value 0.005 and $<0.001$ respectively). No significant difference was seen in the occurrence of hospital acquired pneumonia and mortality outcome (Table 4).

Mean duration of hospital stay was 6 days. Patients who died had a significantly shorter hospital stay at 3 days ( $p$-value $<0.001$ ) reflecting the fulminant course of the disease. Patients who developed pneumonia had a significantly longer hospital stay at 9 days (p-value 0.0021). Mean number of days intubated was significantly higher among those who died at 2 days ( $p$-value $<0.001$ ). Average number of days on hemodialysis was 2 days and average number of hemodialysis sessions was 2 sessions regardless of mortality outcome (Table 5).

Transfusion with platelet concentrate and fresh frozen plasma were significantly higher among patients who died ( $p$-value of $<0.001$ and
0.042 respectively). There was no significant difference seen with the use of packed red blood cells (Table 6).

\begin{tabular}{|l|l|l|l|l|}
\hline & $\begin{array}{l}\text { Total } \\
\mathbf{n = 1 9 4}\end{array}$ & $\begin{array}{l}\text { Lived } \\
\mathbf{n = 1 4 5}\end{array}$ & $\begin{array}{l}\text { Died } \\
\mathbf{n = 4 9}\end{array}$ & p-value \\
\hline $\begin{array}{l}\text { Extra-pulmonary } \\
\text { Bleeding }\end{array}$ & $71(37 \%)$ & $46(32 \%)$ & $25(51 \%)$ & ${ }^{*} 0.005$ \\
\hline $\begin{array}{l}\text { Pulmonary } \\
\text { Hemorrhage }\end{array}$ & $37(19 \%)$ & $5(3 \%)$ & $32(65 \%)$ & $*<0.001$ \\
\hline $\begin{array}{l}\text { Hospital Acquired } \\
\text { Pneumonia }\end{array}$ & $25(13 \%)$ & $21(15 \%)$ & $4(8 \%)$ & 0.432 \\
\hline
\end{tabular}

Table 4: Nosocomial infections and other complications. 


\begin{tabular}{|l|l|l|l|l|}
\hline & $\begin{array}{l}\text { Total } \\
\mathrm{n}=194\end{array}$ & $\begin{array}{l}\text { Lived } \\
\mathrm{n}=\mathbf{1 4 5}\end{array}$ & $\begin{array}{l}\text { Died } \\
\mathrm{n}=\mathbf{4 9}\end{array}$ & $\mathrm{p}$-value \\
\cline { 2 - 5 } Hospital Days & $6 \pm 5$ & $7 \pm 5$ & $3 \pm 3$ & $*<0.001$ \\
\cline { 2 - 5 } & & $\begin{array}{l}\text { Developed } \\
\text { Pneumonia } \\
\mathrm{n}=\mathbf{2 5}\end{array}$ & $\begin{array}{l}\text { No Pneumonia } \\
\mathrm{n}=169\end{array}$ & \\
\cline { 2 - 5 } & $\begin{array}{l}\text { Total } \\
\mathrm{n}=194\end{array}$ & $\begin{array}{l}\text { Lived } \\
\mathrm{n}=145\end{array}$ & $\begin{array}{l}\text { Died } \\
\mathrm{n}=\mathbf{4 9}\end{array}$ & $\mathbf{p}$-value \\
\hline Days Intubated & $1 \pm 2$ & $0.2 \pm 1$ & $2 \pm 2$ & $*<0.001$ \\
\hline $\begin{array}{l}\text { Days } \\
\text { Hemodialysis }\end{array}$ & $2 \pm 2$ & $2 \pm 2$ & $2 \pm 2$ & 0.523 \\
\hline $\begin{array}{l}\text { Number of } \\
\text { Hemodialysis } \\
\text { Sessions }\end{array}$ & $2 \pm 1$ & $2 \pm 1$ & $2 \pm 1$ & 0.994 \\
\hline
\end{tabular}

Table 5: Hospital days and other treatment.

\begin{tabular}{|l|l|l|l|l|}
\hline & $\begin{array}{l}\text { Total } \\
\mathbf{n = 1 9 4}\end{array}$ & $\begin{array}{l}\text { Lived } \\
\mathbf{n = 1 4 5}\end{array}$ & $\begin{array}{l}\text { Died } \\
\mathbf{n = 4 9}\end{array}$ & $\mathbf{p}$-value \\
\hline Packed Red Blood Cell & $17(9 \%)$ & $12(8 \%)$ & $5(10 \%)$ & 0.33 \\
\hline Platelet Concentrate & $19(10 \%)$ & $7(5 \%)$ & $12(24 \%)$ & $*<0.001$ \\
\hline Fresh Frozen Plasma & $6(3 \%)$ & $2(1 \%)$ & $4(8 \%)$ & $* 0.042$ \\
\hline
\end{tabular}

Table 6: Use of blood products.

\section{Discussion}

Leptospirosis is more common in males aged 14 to 44.9 years old probably due to their daily activities or occupational exposure to the pathogen. Risk factors include low socioeconomic status, inadequate sanitation infrastructure, urbanization, inappropriate garbage collection, living along water courses, untreated waste and flooding [10]. In our study, the average age of patients was 37 years old and majority (89\%) of them were male, living in urban areas (NCR 84\%) and unemployed (50\%).

The mortality of leptospirosis with renal failure treated with pulse immunosuppression in this study was $25 \%$ compared to only $12 \%$ mortality reported by Manipol-Lorano et al. in 20148 despite having similar baseline patient demographics. Majority of deaths (16\%) were due to pulmonary hemorrhage, most of whom had a fulminant course with an average hospital stay of 3 days before demise. Virulent forms of leptospirosis are commonly associated with $L$ interrogans serogroup Icterohaemorrhagiae infection [11]. A survey conducted in Metro Manila and Laguna in 2006-2007 identified L interrogans serovar Manilae, serovar Losbanos and serogroup Grippotyphosa and $L$ borgpetersenii serogroup Javanica as the four leptospira serovars and serogroups among rats in the area [12]. Although part of leptospirosis work-up in our institution, microscopic agglutination test (MAT) was not done in majority $(91 \%)$ of the patients primarily due to financial constraint. MAT could have provided serologic diagnosis of leptospirosis since it is possible that a more virulent strain of leptospirosis was the culprit for the higher mortality and more fulminant course of the disease in our patients.

Severe forms of leptospirosis were associated with a delay in antibiotic administration and smoking (particularly with pulmonary involvement). Smokers were three times more likely to develop severe disease probably due to tobacco components that increase the permeability of lung capillaries, damaging alveolar basement membrane and increasing the local inflammatory response [11]. Unfortunately, we did not have data regarding smoking in our patients.

Laboratory findings also found to be associated with severe outcomes include leptospiremia higher than $10^{3} / \mathrm{mL}$ before treatment, acute renal failure, acute pancreatitis, a low platelet count and a high serum lactate level on admission [11]. Ginete et al. in 2010 showed that animal carcass exposure, headache/meningismus, oliguria and serum creatinine $>/=7.1 \mathrm{mg} / \mathrm{dL}$ were predictors for the need for dialysis, while jaundice, hypotension, flood exposure $>4$ hours, pulmonary hemorrhage and platelet count $<100,000 \mathrm{~mm}^{3}$ were predictors of mortality among leptospirosis patients with acute kidney injury [13]. These findings were consistent with our result, as majority $(65 \%)$ of patients who died had pulmonary hemorrhage and their mean platelet count was $64 \pm 56 \times 10^{3} / \mathrm{uL}$. Other predictors of mortality in this study included prolonged PT $(15 \pm 5 \mathrm{sec})$ and presence of parenchymal infiltrates on chest radiograph (63.3\% of patients who died).

Although hospital acquired pneumonia developed in only $13 \%$ of the patients, efforts to mitigate its occurrence can have a big impact particularly on the burden of the disease (longer hospital stay and cost of additional medications). The most common etiology of hospital acquired pneumonia were Staphylococcus aureus, Pseudomonas aeruginosa, Klebsiella species, Escherichia coli, Acinetobacter species and Enterobacter species [14] hence necessitating a change in antibiotics to a broader spectrum agent among our patients. However, we should keep in mind that these patients are also at risk for opportunistic pathogens due to their exposure to immunosuppressive medications.

Acute stages of leptospirosis were characterized by acute tubular necrosis and acute tubulointerstitial nephritis on histopathology. Rapid and complete recovery of renal function is common among mild to moderate acute kidney injury patients when infection is adequately treated and supportive measures given judiciously [15]. Andrade et al. in 2007 showed that prompt and more frequent hemodialysis (daily) to address azotemia and fluid volume decreases the risk for fatal complications in patients with Weil's disease [16]. Patients included in the study underwent daily hemodialysis until recovery of renal function and all patients were weaned off hemodialysis after an average of 2 days regardless of mortality outcome.

Bleeding (epistaxis and gum bleeding to more serious upper gastrointestinal bleeding and pulmonary hemorrhage) was significantly higher among patients who died (51\% vs. 32\%) hence, use of blood products particularly platelet concentrate and fresh frozen plasma were significantly higher among these patients.

Nineteen percent of patients developed pulmonary hemorrhage and among them, $87 \%$ died. This finding is consistent with the report of Ruwanpura et al. in 2012 wherein hemorrhagic form of leptospirosis has been shown to cause pulmonary hemorrhage which conveys over $70 \%$ mortality rate [17]. Because of this, other treatment options aside from antibiotic and supportive care were investigated. 
Page 6 of 6

There has been increasing evidence for an immunologic mechanism mediating renal failure and pulmonary hemorrhagic complications in leptospirosis via an exaggerated host immune response [4,5]. Kularatne et al. in 2011 recommended early administration of methylprednisolone $500 \mathrm{mg}$ IV for 3 days as it may reduce mortality in patients with severe leptospirosis except among patients with established multiple organ dysfunction and co-morbidities (10.7\% vs. $21.8 \%$ mortality rate) [6]. Trivedi et al. in 2009 reported that addition of cyclophosphamide $60 \mathrm{mg} / \mathrm{kg}$ intravenously to standard therapy with methylprednisolone improved patient's survival from pulmonary hemorrhage $(66.7 \%$ vs. $9.4 \%$ survival rate) with minor side effects (leukopenia and alopecia) [7].

It was evident that renal failure recovered with hemodialysis support while leptospirosis was being treated with antibiotics and pulse immunosuppression. However, when patient develops pulmonary hemorrhage, majority died from respiratory failure despite mechanical ventilation. Thus there is a need for more effective pulmonary support while the lungs recover.

Recently, several case reports describing the successful use of Extracorporeal Membrane Oxygenation (ECMO) among patients with pulmonary hemorrhage have been reported $[18,19]$. ECMO was conventionally used in severe acute respiratory distress syndrome, massive hemoptysis and critical tracheal stenosis. It relieves the lung of its gaseous exchange function and minimizes further lung injury caused by mechanical ventilation with high $\mathrm{FiO}_{2}$, tidal volume and airway pressure. However, there is still paucity of evidence with regards to the use of ECMO among patients with leptospirosis and its use is limited mainly by availability, high cost and need of experienced staff.

\section{Conclusion and Recommendation}

There was $25 \%$ mortality among patients diagnosed with leptospirosis with renal failure treated with pulse immunosuppression with majority dying of pulmonary hemorrhage. Abnormal bleeding parameters and parenchymal infiltrates on chest radiograph significantly predicted death hence transfusion of platelet concentrate and fresh frozen plasma were more common among these patients. Renal function recovered within 2 days of treatment regardless of mortality outcome. Hospital acquired pneumonia developed in $13 \%$ of the patients and resulted in a significantly longer hospital stay but had no significant effect on mortality outcome. Pulse immunosuppression remains a part of the standard of care of leptospirosis with renal failure in our institution based on the best available evidence to date. However, we still need prospective study to provide higher quality of evidence with its use. We also need to acknowledge the attendant risk of nosocomial infection with the use of these medications. Elderly, diabetics, malnourished and immune-compromised patients might benefit with lower doses of immunosuppression or use of prophylactic antibiotics.

Pulmonary supportive therapy such as ECMO is a promising treatment that may provide pulmonary support, allowing time for the lungs to recover from severe injury and improve patient's overall survival.

\section{Author's Disclosure}

The study received institutional research funding.

\section{References}

1. Kasper DL, Fauci AS, Hauser SL, Longo DL, Jameson JL, et al. (2015) Harrison's principles of internal medicine (19th edn), New York, USA; McGraw Hill Professional.

2. Leptospirosis (2017) Centers for Disease Control and Prevention. US Department of Health \& Human Services, Atlanta, USA.

3. Leptospirosis (2012) World Health Organization. Manila Philippines: World Health Organization; Western Pacific Region.

4. Klimpel GR, Matthias MA, Vinetz JM (2003) Leptospira interrogans activation of human peripheral blood mononuclear cells preferential expansion of $\mathrm{TCR} \gamma \delta+\mathrm{T}$ cells vs TCR $\alpha \beta+\mathrm{T}$ cells. J Immunol 171: 1447-1455.

5. Nally JE, Chantranuwat C, Wu XY, Fishbein MC, Pereira MM, et al. (2004) Alveolar septal deposition of immunoglobulin and complement parallels pulmonary hemorrhage in a guinea pig model of severe pulmonary leptospirosis. Am J Pathol 164: 1115-1127.

6. Kularatne SA, Budagoda BD, de Alwis VK, Wickramasinghe WM, Bandara JM, et al. (2011) High efficacy of bolus methylprednisolone in severe leptospirosis a descriptive study in Sri Lanka. Postgrad Med J 87: 13-17.

7. Trivedi SV, Vasava AH, Patel TC, Bhatia LC (2009) Cyclophosphamide in pulmonary alveolar hemorrhage due to leptospirosis. Indian J Crit Care Med 13: 79-84.

8. Manipol-Lorano RJ, Danguilan RA, Santos S, Chavez J, Mendoza MT (2014) Effect of methylprednisolone and cyclophosphamide on the survival of patients with leptospirosis, renal failure and pulmonary hemorrhage. Trop Med Surg 2: 171.

9. Danguilan RA, Arakama MI (2013) Leptospirosis: Emergency policies and procedures manual. National Kidney and Transplant Institute, Quezon City, Philippines.

10. Jesus MS, Silva LA, Lima KM, Fernandes OC (2012) Cases distribution of leptospirosis in city of Manaus, state of Amazonas, Brazil, 2000-2010. Rev Soc Bras Med Trop 45: 713-716.

11. Tubiana S, Mikulski M, Becam J, Lacassin F, Lefèvre P, et al. (2013) Risk factors and predictors of severe leptospirosis in New Caledonia. PLoS Negl Trop Dis 7: e1991.

12. Villanueva SY, Ezoe H, Baterna RA, Yanagihara Y, Muto M, et al. (2010) Serologic and molecular studies of leptospira and leptospirosis among rats in the Philippines. Am J Trop Med Hyg 82: 889-898.

13. Ginete JK, Mendoza MT (2010) Predictors of dialytic management and mortality among leptospirosis patients with acute renal failure at the National Kidney and Transplant Institute. J Nephrol Therapeut 2: 5.

14. Jones RN (2010) Microbial etiologies of hospital-acquired bacterial pneumonia and ventilator-associated bacterial pneumonia. Clin Infect Dis 51: S81-87.

15. Herath NJ, Kularatne SA, Weerakoon KG, Wazil A, Subasinghe N, et al. (2014) Long term outcome of acute kidney injury due to leptospirosis? a longitudinal study in Sri Lanka. BMC Res Notes 7: 398.

16. Andrade L, Cleto S, Seguro AC (2007) Door-to-dialysis time and daily hemodialysis in patients with leptospirosis impact on mortality. Clin J Am Soc Nephrol 2: 739-744.

17. Ruwanpura R, Rathnaweera A, Hettiarachchi $M$, Dhahanayake $K$, Amararatne S (2012) Severe pulmonary leptospirosis associated with high fatality rate an autopsy series in Galle, Southern Sri Lanka. Med J Malaysia 67: 595-600.

18. Liao CY, Ben RJ, Wu HM, Chang SK, Liu MY, et al. (2015) Acute respiratory distress syndrome manifested by leptospirosis successfully treated by extracorporeal membrane oxygenation (ECMO). Intern Med 54: 2943-2946.

19. Cantwell T, Ferre A, Van Sint Jan N, Blamey R3, Dreyse J, et al. (2017) Leptospirosis-associated catastrophic respiratory failure supported by extracorporeal membrane oxygenation. J Artif Organs 20: 371-376. 